\title{
LEAN SERVICE: APLICAÇÃO DO MAPEAMENTO DO FLUXO DE VALOR EM UMA ORGANIZAÇÃO DE SERVIÇOS
}

\section{LEAN SERVICE: APPLICATION OF THE VALUE STREAM MAPPING IN A SERVICE ORGANIZATION}

\author{
Darlan José Roman ${ }^{1}$; Jamur Johnas Marchi ${ }^{2}$; Fernando Antônio Forcellini ${ }^{3}$; Rolf Hermann \\ Erdmann ${ }^{4}$ \\ ${ }^{1}$ Universidade Federal de Santa Catarina - UFSC - Florianópolis - Brasil \\ darlanroman@yahoo.com.br \\ ${ }^{2}$ Universidade Federal de Santa Catarina - UFSC - Florianópolis - Brasil \\ ${ }^{2}$ Universidade Federal do Pampa - Unipampa - Santana do Livramento - Brasil \\ jamur.marchi@unipampa.edu.br \\ ${ }^{3}$ Universidade Federal de Santa Catarina - UFSC - Florianópolis - Brasil \\ forcellini@deps.ufsc.br \\ ${ }^{4}$ Universidade Federal de Santa Catarina - UFSC - Florianópolis - Brasil \\ erdmann@cse.ufsc.br
}

\begin{abstract}
Resumo
Neste artigo desenvolve-se a aplicação do Mapeamento do Fluxo de Valor (MFV) em uma corretora de seguros. $O \mathrm{MFV}$ é uma das principais ferramentas e um dos primeiros passos para implementar a mentalidade lean nas organizações. A fonte de vantagem competitiva no setor de seguros pode estar residindo nos processos responsáveis pela captação da real necessidade do cliente e sua materialização na venda do produto final, a apólice. Desta forma, o MFV apresentase como um importante instrumento para auxiliar as organizações de seguros na redução de desperdícios do processo produtivo e, consequentemente, na geração de valor para o cliente. A metodologia de aplicação seguiu os procedimentos sugeridos por Rother e Shook (2003). Percebese que a abordagem Lean pode trazer significativas contribuições para a análise de processos em organizações do setor de seguros. Notadamente, na dimensão tempo, acreditando que o cliente que deseja contratar um seguro queira fazê-lo o no menor tempo possível.
\end{abstract}

Palavras-chave: lean service; corretora de seguros; gestão de serviços.

\section{Introdução}

O setor de serviços de seguro é um dos setores que mais tem crescido em termos de concorrência acirrada, aonde a diferenciação dos produtos pode representar significativas vantagens competitivas (ZILBER e BRANCALIÃO, 2008). De fato, o setor é reconhecidamente competitivo, porém a vantagem competitiva pode não estar apenas nos produtos oferecidos. Isto pode ser notado, nas diferenças de preço mínimas entre concorrentes no setor. Uma alternativa que empresas de 
seguro têm oferecido, visando atrair clientes, são os pacotes de serviços agregados, por exemplo, as assistências domiciliares.

Contudo, uma fonte de vantagem competitiva neste setor pode estar residindo nos processos responsáveis pela captação da real necessidade do cliente e sua materialização na venda do produto final, a apólice. Antes deste momento ou após, dificilmente empresa e cliente irão ter um contato mais próximo, salvo em caso de algum sinistro. Este momento, geralmente esta sob a responsabilidade de empresas de corretagem de seguros e não das seguradoras. A competição entre as empresas de corretagem mostra-se mais acirrada ainda, pois estas irão se diferenciar essencialmente nos atributos ligados ao processo de captação da real necessidade do cliente e sua efetiva materialização através do produto final: a apólice de seguro.

O estado de Santa Catarina tem uma participação expressiva no mercado de seguros do país, contando com 2.063 corretoras de seguros cadastradas junto ao Sindicato das Corretoras de Seguros/SC (SINCOR), segundo Zoschke e Pereira (2007). A empresa em que o estudo foi realizado é a Oriento Consultoria e Corretora de Seguros Ltda, com sede em Blumenau e filial em Florianópolis - SC. O mapeamento do fluxo de valor foi realizado na filial, tomando o processo de "venda de proposta de seguro automóvel", que conforme Zoschke e Pereira (2007) tem importância significativa na composição da carteira da corretora.

Neste sentido, este artigo procura abordar a metodologia de Mapeamento do Fluxo de Valor (MFV), seguindo as ideias do Lean Service. Esta metodologia é uma alternativa para que empresas consigam captar a real necessidade de seus clientes e concretizá-las através da aplicação de princípios lean em seus processos de serviço. As empresas do setor de corretagem de seguros, essencialmente prestadoras de serviços, podem fazer uso destes conceitos e métodos a fim de melhorar seus processos. Com isso tais empresas podem oportunizar aos seus clientes mais valor.

Este artigo tem por objetivo analisar o processo da aplicação da metodologia de Mapeamento do Fluxo de Valor (MFV) na operacionalização do Lean Service em uma empresa de serviços de corretagem de seguros situada em Florianópolis-SC. Para tanto, uma seção inicial apresenta os conceitos do pensamento lean, lean service e mapeamento de fluxo de valor. Depois, desenvolveu-se um estudo do processo principal da empresa, seguindo a metodologia do MFV, aonde foram desenvolvidos os mapas de estado atual e futuro do processo analisado. Os resultados são discutidos e considerações teóricas e práticas são tecidas ao final do trabalho.

\section{Pensamento lean}

Dentre os diferentes modelos de gestão da produção que surgiram no século XX e que permanecem em evidência no século atual, a Produção Enxuta representa, seguramente, um dos modelos mais difundidos. A simplicidade de seus princípios, associada ao forte apelo para a 
eliminação de perdas nos processos produtivos, justificam, pelo menos em parte, o grande interesse da comunidade empresarial em torno do tema (SANTOS et al, 2011).

O termo Lean Production foi primeiramente usado por Krafcik em 1988 e, subsequentemente, Womack et al usaram o termo Lean Production como contraste do Sistema Toyota de Produção com o sistema ocidental de produção em massa no livro "A máquina que mudou o mundo" (HOLWEG, 2007). Desta forma, o sistema japonês de produção passou a ter uma versão ocidental.

O Sistema Toyota de Produção foi pouco conhecido até os anos 1973. A partir de então, com a primeira crise do petróleo, o STP começa a ser objeto de maior atenção. Com a crie do petróleo também se reiniciou o interesse por pesquisas ligadas ao futuro da indústria automobilística. O ponto de partida para as investigações foi o IMVT (International Motor Vehicle Program) vinculado ao MIT (Massachusetts Institute of Technology) (HOLWEG, 2007).

O livro "A máquina que mudou o mundo" que introduziu em larga escala o termo "lean production", em 1990, se tornou uma das referências mais largamente citadas em gerência de produção nos últimos anos (HOLWEG, 2007). O sucesso deste livro pode ser atribuído à clareza dos conceitos e à forma convincente e organizada de apresentação dos resultados obtidos a partir da implementação do pensamento enxuto por empresas de todo o mundo.

A publicação do livro "A máquina" desencadeou uma rica investigação no âmbito da adoção de práticas atreladas ao pensamento enxuto, que ficaram inicialmente restritas ao setor automotivo, mas que brevemente se expandiu para outros setores de manufatura e de serviços (HOLWEG, 2007). Além do tradicional lean production outros termos passam a constituir o arcabouço do pensamento enxuto, a exemplo do lean service, do lean office e do lean design.

Em suma, o pensamento lean é tratado desta forma porque é uma maneira de fazer cada vez mais com cada vez menos. Ou seja, se produz mais com menos esforço humano, menos equipamento, menos tempo e menos espaço. Ao mesmo tempo, a intenção é aproximar-se cada vez mais de oferecer aos clientes exatamente o que eles desejam. Nesta conformidade, o conceito de flexibilidade desponta como critério diferenciador nos sistemas de produção que usufruem do pensamento enxuto.

O ponto de partida essencial para o pensamento lean é o valor. $\mathrm{O}$ valor só pode ser definido pelo cliente final. E só é significativo quando expresso em termos de um produto específico (um bem ou um serviço e, muitas vezes, ambos simultaneamente) que atenda às necessidades do cliente a um preço específico em um momento específico, com características específicas (WOMACK; JONES, 2004).

A capacidade de eliminar a perda na produção é desenvolvida a partir do momento em que se deixa de acreditar que "não há outra maneira" de executar uma dada tarefa. É inútil dizer: "Isso 
tem que ser feito desse jeito", ou "Isso é inevitável" (SHINGO, 1996). Nestes termos, os problemas passam a ser vistos como oportunidades de melhoria, seja no produto, processo ou relacionamento com fornecedores e clientes.

O pensamento lean inclui ferramentas e formas sistêmicas de eliminação de perdas, pela concepção e projeto de produtos e processos e melhoria em atividades, interfaces e fluxos entre processos internos e externos (SELLITTO et al, 2010). O conceito de fluxo de valor estendido permite entender a possibilidade de sincronização de processos com fornecedores.

São apresentados por Womack e Jones (2004) os cinco princípios básicos da mentalidade lean:

Valor: definir o que é Valor. Não é a empresa e sim o cliente que define o que é valor;

- Fluxo de Valor: consiste em identificar os processos que geram valor, aqueles que não geram valor, mas são importantes para a manutenção dos processos e da qualidade e, por fim, aqueles que não agregam valor e que devem ser eliminados;

- Fluxo: deve-se dar "fluidez" para os processos e atividades que restaram;

- Produção Puxada: Conectam-se os processos através de sistemas puxados;

- Perfeição: A busca do aperfeiçoamento contínuo em direção a um estado ideal deve nortear todos os esforços da empresa.

\subsection{Lean service}

Atualmente as indústrias de serviços são a fonte de liderança econômica em muitos países. “É imperativo reconhecer que os serviços não são atividades meramente periféricas, mas parte integrante da sociedade e estão presentes no cerne da economia, sendo fundamentais para que esta se mantenha sadia e funcional" (FITZSIMMONS; FITZSIMMONS, 2005, p. 30).

O reconhecimento das características especiais da prestação de serviços e a sua comparação com o setor de manufatura constituem a base para um gerenciamento inovador e com melhores condições de competir no mercado. Assim como na manufatura, o cliente não quer pagar pelo desperdício ou pela falta de eficiência da empresa. Sendo assim, é fundamental implementar continuamente melhorias nos processos de forma a aproveitar melhor os recursos disponíveis. Nesta conformidade, é possível identificar a aplicação de conceitos da produção enxuta para serviços em setores como saúde, seguros, finanças e assistência técnica (WOMACK et al, 1992; SELAU et al, 2009).

A racionalidade gerencial encorpada na prática que se vê normalmente presente em ambientes de manufatura pode ser aplicada, sem muito esforço, aplicada com similaridade, obtendo resultados semelhantes, nas indústrias de serviço (LEVITT, 1976). Nas últimas décadas, muitas 
empresas de serviços têm adotado os princípios da "lean manufacturing", resultando em uma reindustrialização dos serviços (SELAU et al, 2009).

Com a aplicação da abordagem de manufatura para serviços, é possível às companhias de serviços alcançarem eficiência, baixo custo de produção e clientes satisfeitos. Na visão de Selau et al, (2009) o fator de sucesso de algumas empresas (Southwest airlines e Macdonalds) pode ser explicado pelo pioneirismo das mesmas em adotar o conceito de lean manufacturing para o ambiente dos serviços. Adotando práticas associadas com o lean manufacturing - por exemplo, a orientação da cadeia de valor e empowerment - estas empresas se tornaram modelos de sucesso no ambiente dos serviços.

As empresas de serviços precisam como adotar como pré-condição para alta eficiência e baixo custo os mesmos tipos de disciplinas e estratégias que fazem as empresas de manufatura tão eficientes. Eficiência em serviços pode requerer altos investimentos instalações, terrenos, equipamentos, além de planejamento, organização, treinamento e controle, comparável aos investimentos associados para conseguir eficiência na manufatura (LEVITT, 1976),

Destarte, o conceito de lean service pode ser entendido como o emprego das técnicas e ferramentas presentes na filosofia lean no ambiente de serviços. Para Selau et al, (2009) existe um "paradigma industrial comum" emergindo em que uma lógica similar está encontrando apelo nos setores de manufatura e serviços. Levando em consideração as aparentes similaridades existentes entre processos de manufatura e serviços, acredita-se ser possível conferir maior competitividade às empresas de serviços por meio da redução de desperdícios e criação de valor para o cliente, a partir da consideração da abordagem do lean service.

\subsection{Mapeamento do fluxo de valor}

O fluxo de valor é o conjunto de todas as ações específicas necessárias para se levar um produto específico a passar pelas três tarefas gerenciais críticas em qualquer negócio: a tarefa de solução de problemas, a tarefa de gerenciamento da informação e a tarefa de transformação física (WOMACK; JONES, 2004). O mapeamento eficiente do fluxo de valor deve criar uma situação onde seja possível identificar os desperdícios, ou seja, as atividades que não geram valor para o cliente.

As principais técnicas existentes para a representação das atividades de um processo são os fluxogramas, os mapofluxogramas, o blueprint, as técnicas IDEF e o mapeamento do fluxo de valor

(SALGADO et al, 2009). Este último é a principal ferramenta utilizada quando o objetivo é identificar ou implantar os princípios subjacentes ao pensamento enxuto no âmbito de sistemas produtivos. 
Com base na premissa de que o fluxo de valor é representado pelo conjunto de ações existentes no processo produtivo que (agregando valor ou não) são responsáveis por levar o produto até o cliente, Rother e Shook (2003) apresentam o mapeamento do fluxo de valor (MFV) como uma ferramenta que dá suporte à estruturação de um sistema de produção enxuta (SANTOS et al, 2011). O MFV é um método funcional com o objetivo de reorganizar sistemas de produção a partir da visão lean (LASA et al, 2008)

O mapeamento do fluxo de valor é uma ferramenta essencial para o sistema de produção enxuta, que permite às empresas enxergarem todo o fluxo de valor do seu processo produtivo. $\mathrm{O}$ mapeamento é uma ferramenta de comunicação, planejamento e gerenciamento de mudanças, que direciona as tomadas de decisões das empresas em relação ao fluxo, possibilitando ganhos em indicadores de qualidade e produtividade interessantes (ELIAS et al, 2011).

Algumas características essenciais da ferramenta mapeamento do fluxo de valor são apontadas por Rother e Shook (2003):

- Ajuda a visualizar mais do que simplesmente os processos individuais, por exemplo, montagem, solda, etc. Você pode enxergar o fluxo todo;

- Ajuda a identificar mais do que os desperdícios. Mapear ajuda a identificar as fontes de desperdícios no fluxo de valor;

- Fornece uma linguagem comum para tratar os processos de manufatura;

- Torna as decisões sobre os fluxos visíveis, de modo que você pode discuti-las. De outro modo, muitos detalhes e decisões no chão de fábrica só acontecem por omissão;

- Junta conceitos e técnicas enxutas, que o ajuda a evitar a implementação de algumas técnicas isoladamente;

- Forma a base de um plano de implementação. Ao ajudá-lo a desenhar como o fluxo total de porta a porta deveria operar - uma parte que falta em muitos esforços enxutos - os mapas do fluxo de valor tornam-se referência para a implementação enxuta. Imagine tentar construir uma casa sem uma planta;

- Mostra a relação entre o fluxo de informação e o fluxo de material. Nenhuma outra ferramenta faz isso;

É muito mais útil que ferramentas quantitativas e diagramas de layout que produzem um conjunto de passos que não agregam valor, lead time, distância percorrida, a quantidade de estoque, e assim por diante.

De fato, o MFV é mais abrangente que uma técnica comum de mapeamento de processos, com procedimentos definidos e simbologia própria, mas representa uma metodologia de referência para a implantação da produção enxuta. Com esse objetivo, o MFV se preocupa em mapear os fluxos de materiais e de informações de um processo ou de uma cadeia de valor, descrevendo o 
estado atual do processo e orientando a obtenção de um estado futuro que inclui a adoção de práticas de produção enxuta (SANTOS.et al, 2011),

O mapeamento do fluxo de valor deve seguir, segundo Rother e Shook (2003), as seguintes etapas:

- Escolha da família de produtos: Selecionar uma família de produtos composta por um grupo de produtos que passam por etapas semelhantes de processamento;

- Desenho o estado atua e futuro: Desenhar o estado atual e o estado futuro, o que é feito a partir de informações coletadas no chão de fábrica;

- Plano de trabalho e implementação: Preparar um plano de implementação que descreva, em uma página, como se deseja chegar ao estado futuro.

Com esta ferramenta é possível identificar no detalhe cada processo do fluxo, determinando o lead time por meio de estoques de matéria prima, em processo e produto acabado. O MFV caracteriza-se também por ser um método visual de fácil compreensão, que permite enxergar os desperdícios de estoque, de superprodução e de processo, entre outros benefícios (ELIAS et al, 2011)

\section{Metodologia}

Para alcançar os objetivos deste trabalho elaborou-se o mapeamento do fluxo de valor, uma das principais ferramentas indicadas para a implantação e acompanhamento dos princípios da mentalidade enxuta. Seguiu-se o roteiro estabelecido por Rother e Shook (2003), que desenvolveram um manual prático para uso empresarial que estabelece uma sequência lógica de etapas.

A metodologia de mapeamento do fluxo de valor é composta por quatro etapas básicas: (1) seleção de uma família de produtos, (2) mapeamento do estado atual, (3) mapeamento do estado futuro e (4) plano de trabalho e implementação. Neste trabalho foram empreendidas as três primeiras etapas. O plano de trabalho e implementação encontra-se em fase de análise por parte da gerência da empresa.

A seleção de uma família de produtos é necessária quando uma empresa possui diferentes fluxos de valor em relação a seu mix total de produtos. No presente estudo selecionou-se a família de produtos de seguros automotivos. Em seguida, escolheu-se o produto mais importante desta família para então iniciar o mapeamento do estado atual. Por meio de uma folha de etapas do processo foram coletados os dados do processo.

O mapa do estado atual é elaborado para que se obtenha uma visão global do fluxo de valor e dos desperdícios a ele associados. Nesta fase, foi tirada uma "fotografia" dos processos e operações, a fim de se conhecer exatamente as características do processo produtivo. A elaboração 
do MEA (Mapa do Estado Atual) foi realizada em conjunto com a gerência da empresa e a confecção do mesmo se deu com o auxílio do software Quality Companion 3 versão Trial Este primeiro encontro com a gerência teve a duração de 60 minutos.

O mapeamento do estado futuro sucede a elaboração do mapa atual e incorpora as oportunidades de melhoria identificadas na etapa anterior. Nesta fase, os pesquisadores se reuniram novamente com a gerência da organização de forma a apresentar o mapa do estado atual e validar as sugestões de melhoria que iriam se refletir no mapa do estado futuro. Esse encontro teve a duração de 50 minutos.

\section{Resultados e desenvolvimento do trabalho}

O objetivo deste trabalho é realizar um exercício de mapeamento do fluxo de valor em uma empresa prestadora de serviços. A empresa selecionada atua no setor de serviços de corretagem de seguros. Tal seleção foi guiada pela conveniência e oportunidade de observar como os princípios Lean podem ser aplicados fora do ambiente de manufatura.

O trabalho foi executado conforme as fases:

1) Definir produto ou família de produto: esta fase foi realizada através de uma reunião com a gerente e proprietária da empresa, com duração de 60 minutos. Neste encontro, pode-se tomar conhecimento geral da empresa e definir a processo de "venda de seguro automóvel" como um dos principais processos de trabalho. Além disso, tal produto possui significativa importância na composição da carteira da empresa.

2) Mapear o estado atual do processo de produção: definido o processo a ser mapeado, na mesma reunião, colocou-se em prática a fase 2 , onde através de uma folha de etapas do processo (Quadro 1) foram coletados os dados do processo.

\begin{tabular}{|c|c|c|c|c|c|}
\multicolumn{7}{|c|}{ Quadro 1- Exemplo de folha de etapas do processo } \\
\hline $\begin{array}{c}\text { Etapas do } \\
\text { Processo }\end{array}$ & $\begin{array}{c}\text { Pessoas e } \\
\text { Tecnologias }\end{array}$ & $\begin{array}{c}\text { Índices } \\
\text { Tempo Ciclo } \\
\text { Tempo Valor agregado }\end{array}$ & $\begin{array}{c}\text { Entradas } \\
\text { Estoques e } \\
\text { Tempo de } \\
\text { Espera }\end{array}$ & $\begin{array}{c}\text { Saídas } \\
\text { Estoques e } \\
\text { Tempo de } \\
\text { Espera }\end{array}$ & $\begin{array}{c}\text { Outras } \\
\text { informações }\end{array}$ \\
\hline 1 & & & & & \\
\hline 2 & & & & & \\
\hline$\ldots$ & & & & & \\
\hline $\mathrm{N}$ & & & & & \\
\hline
\end{tabular}

Fonte: Autoria própria (2012) 
Primeiro, foi preenchida a coluna das etapas do processo. Em seguida, as demais colunas foram sendo completadas com as informações disponíveis pela empresa. O método de coleta de dados foi através da observação direta sobre o processo e entrevista com a gerente da empresa.

A elaboração do MEA (Mapa do Estado Atual) foi realizada através do auxílio do software Quality Companion 3 versão Trial, conforme apresentado na Figura 1. Os índices que puderam ser operacionalizados no mapa foram: tempo de ciclo (Cycle time), tempo de valor agregado (VA Cycle time), tempo de valor não agregado (NVA Cycle time) e lead time. Após a confecção do MEA, estes índices obtiveram valores totais, conforme a Tabela 1 .

Tabela 1- Índices totais para o MEA

\begin{tabular}{ll}
\hline Índice & Valor \\
\hline Tempo de ciclo total & $168 \mathrm{~h}$ \\
Tempo de VA & $20,33 \mathrm{~h}$ \\
Tempo de NVA & $147,67 \mathrm{~h}$ \\
Lead time & $192 \mathrm{~h}$ \\
\hline
\end{tabular}

Fonte: Pesquisa de campo (2012)

3) Validar mapa do estado atual: após a confecção do MEA, foi agendada outra reunião junto à empresa com o objetivo de validar o mapa atual, principalmente em termo de fluxo e índices. A reunião foi de aproximadamente 60 minutos. O MEA apresentado foi aceito totalmente pela gerente da empresa. Nesta mesma reunião foi discutido com a gerência da empresa sugestões de melhoria para o MEA, objetivando levantar subsídios para a análise de MEA, visando já o mapa do estado futuro. O principal subsídio foi relacionado ao atendimento inicial ao cliente, envolvendo as etapas do processo: análise do risco e cotação. 
Figura 1: Mapa do estado atual (MEA)

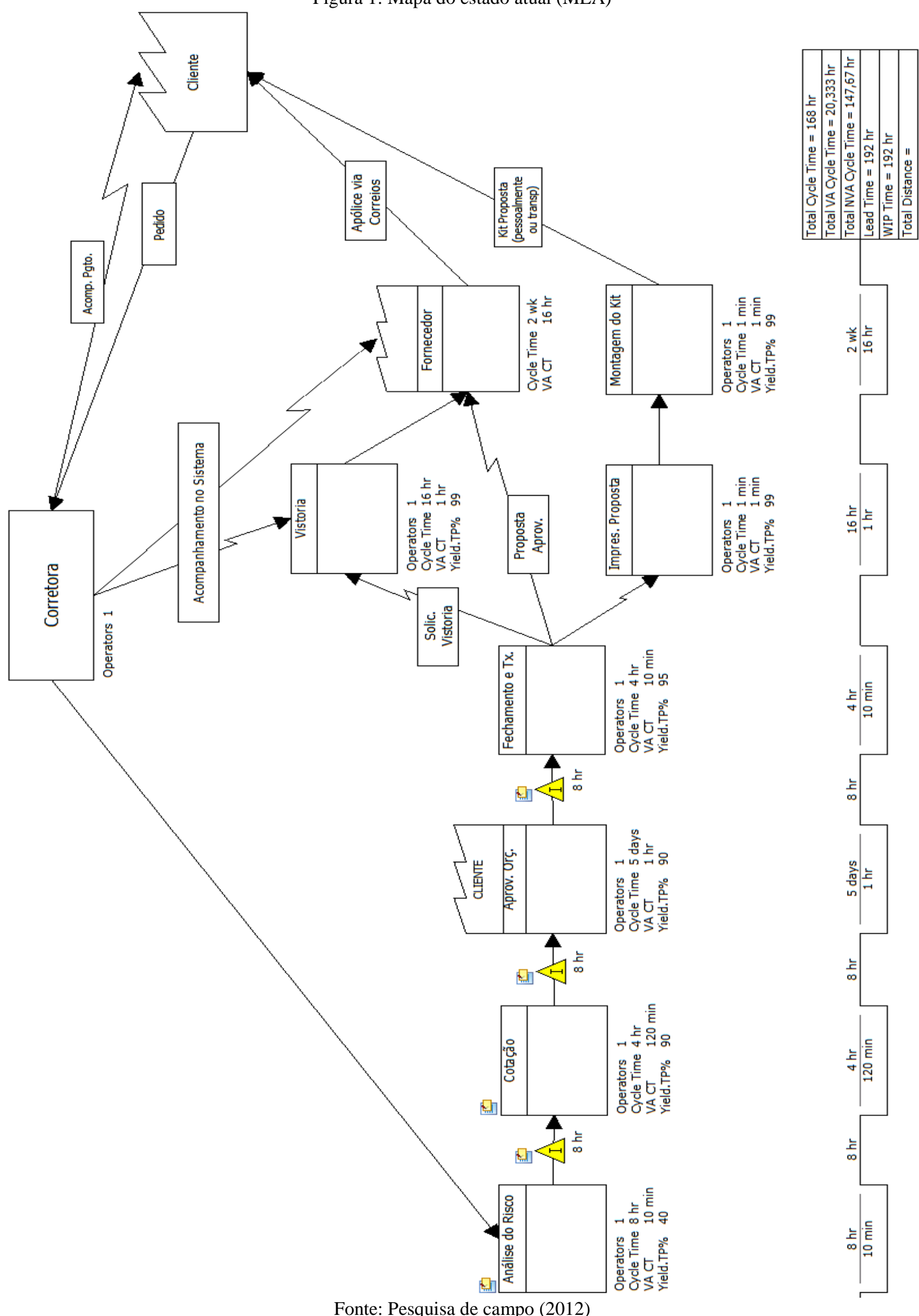


4) Analisar MEA: a análise do MEA foi realizada então pelos pesquisadores, no campus universitário. De posse das impressões obtidas junto à gerência da empresa e análise dos desperdícios no processo, observaram-se atividades que agregam valor e outras que geram desperdícios ao processo. Três possíveis áreas de melhoria foram observadas, conforme a Figura 2. Discutiram-se as três áreas seguindo graus decrescentes de urgência:

a) Frente de atendimento ao cliente: a área de atendimento ao cliente tem apresentado limitações evidenciadas pelo índice baixo de qualidade da informação gerada no cadastro do cliente visando à análise de risco (veja no MEA, na atividade "análise do risco" o Yield TP\% 40). A espera para cotação ocorre porque o contato com o cliente é pouco próximo, sendo muitas vezes realizado eletronicamente. Com isso, ocorrem esperas para que o cliente preencha o formulário com seus dados (muitas vezes o cliente preenche parcialmente, ocasionando retrabalho) para viabilizar as cotações.

Quando o processo chega à etapa de cotação, a política da empresa é realizar sempre seis cotações em seis diferentes fornecedores (seguradoras) o que demanda um tempo elevado e mais um tempo de espera para que o cliente analise e aprove um dos orçamentos. Como muitas vezes, o cliente recebe por email as cotações, existe uma espera até a aprovação. Outra espera ocorre após a aprovação, pois o cliente precisa ir até a empresa para assinar a proposta. Somente após a assinatura é que a proposta pode ser fechada e transmitida.

Apesar de se acreditar que através de email, se esta facilitando a vida do cliente, por outro lado, o tempo desde o momento em que o cliente externa a necessidade do serviço até o fechamento acaba sendo elevado.

b) Seleção de fornecedores: outro problema observado e que pode ser passível de melhoria reside na seleção de fornecedores da corretora. Segundo a corretora nem todos os fornecedores aceitam segurar (momento em que o cliente recebe valor) o cliente logo após a assinatura da proposta, com isso muitos clientes precisam esperar a vistoria e a emissão da apólice. Apesar de não ser para todos, alguns clientes acabam por esperar entre 2 e 4 dias para estar com o veículo segurado.

c) Operacional: este problema, na verdade, é bastante simples e apenas refere-se a uma melhoria na relação entrega de valor ao cliente e imagem da empresa. Esta melhoria pode ocorrer entre as etapas de impressão e montagem do kit da corretora ao cliente. 


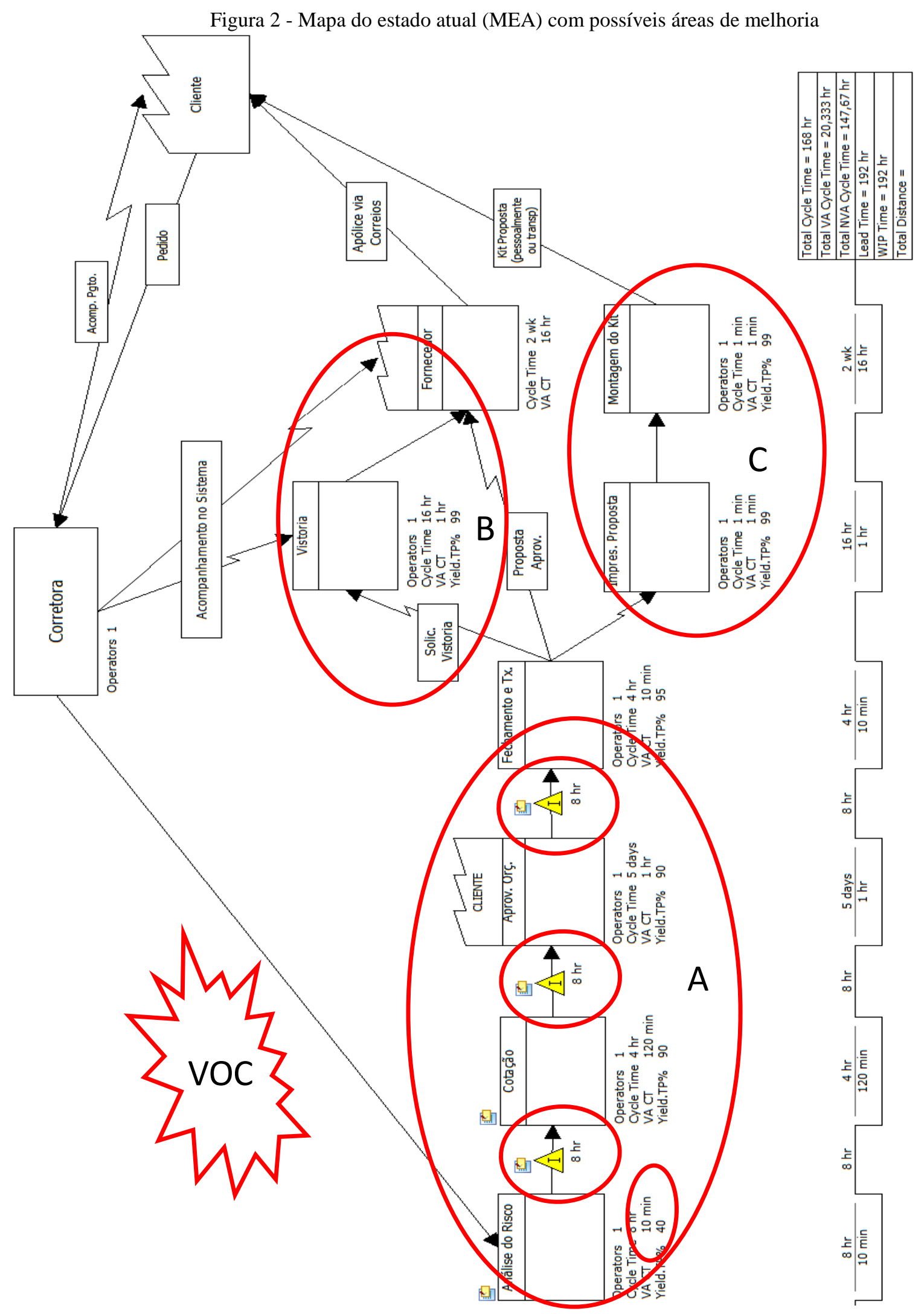

Fonte: Pesquisa de campo (2012)

5) Proposição do mapa do estado futuro (MEF) do processo: após a análise do MEA, foi desenvolvido o mapa do estado futuro, com o objetivo de representar a situação futura desejável para o processo estudado. O mapa do estado futuro poderá ser alcançado na medida em que a 
empresa atuar nas três áreas abordadas no item anterior. A título de sugestão, definiram-se algumas ações que podem servir de orientação para o planejamento das ações de melhoria no processo:

\section{a) Frente de atendimento ao cliente;}

a.1) Formar célula de atendimento e cotação;

a.1.1) Alocar um especialista em fechamento de vendas de seguros para atender os clientes, visando 'escutar a voz do cliente';

a.1.2) O cliente deve ser esclarecido da importância das informações prestadas para a análise do risco;

a.1.3) Alterar a política de cotação para até três fornecedores;

a.1.4) Com isso, agilizar a etapa de cotação;

a.1.5) Definir a seleção com o cliente.

Com essas medidas, sugere-se que as etapas análise de risco, cotação e aprovação do orçamento sejam agrupadas em célula, formada por um especialista em vendas e um operador para cotação da proposta. Na medida em que a empresa necessitar, o número de célula pode ser ampliado e/ou dirigido por perfis diferenciados de clientes.

\section{b) Seleção de fornecedores;}

b.1) Desenvolver uma carteira de fornecedores que permitam antecipar a entrega de valor ao cliente, no caso, segurar o cliente no fechamento da proposta;

b.1.1) Negociar com seguradoras e firmar parceiras visando a antecipação da entrega de valor.

Assim, a empresa terá uma carteira de fornecedores que antecipem valor aos clientes, eliminando os tempos em vistoria e emissão da apólice para o cliente.

\section{c) Operacional;}

c.1) Assegurar a imagem de marca da empresa no momento de entrega de valor;

c.1.1) O kit montado é entregue na ocasião da saída do cliente da empresa.

Quanto ao fechamento, transmissão, impressão e montagem do kit, apesar de etapas diferentes, podem ser realizadas por um mesmo operador. Esta medida simples visa adequar a imagem da empresa (através do kit) ao momento em que o cliente recebe valor.

Após as mudanças no processo o MEF pode ser representado como na Figura 3. 
Figura 3 - Mapa do estado futuro (MEF)

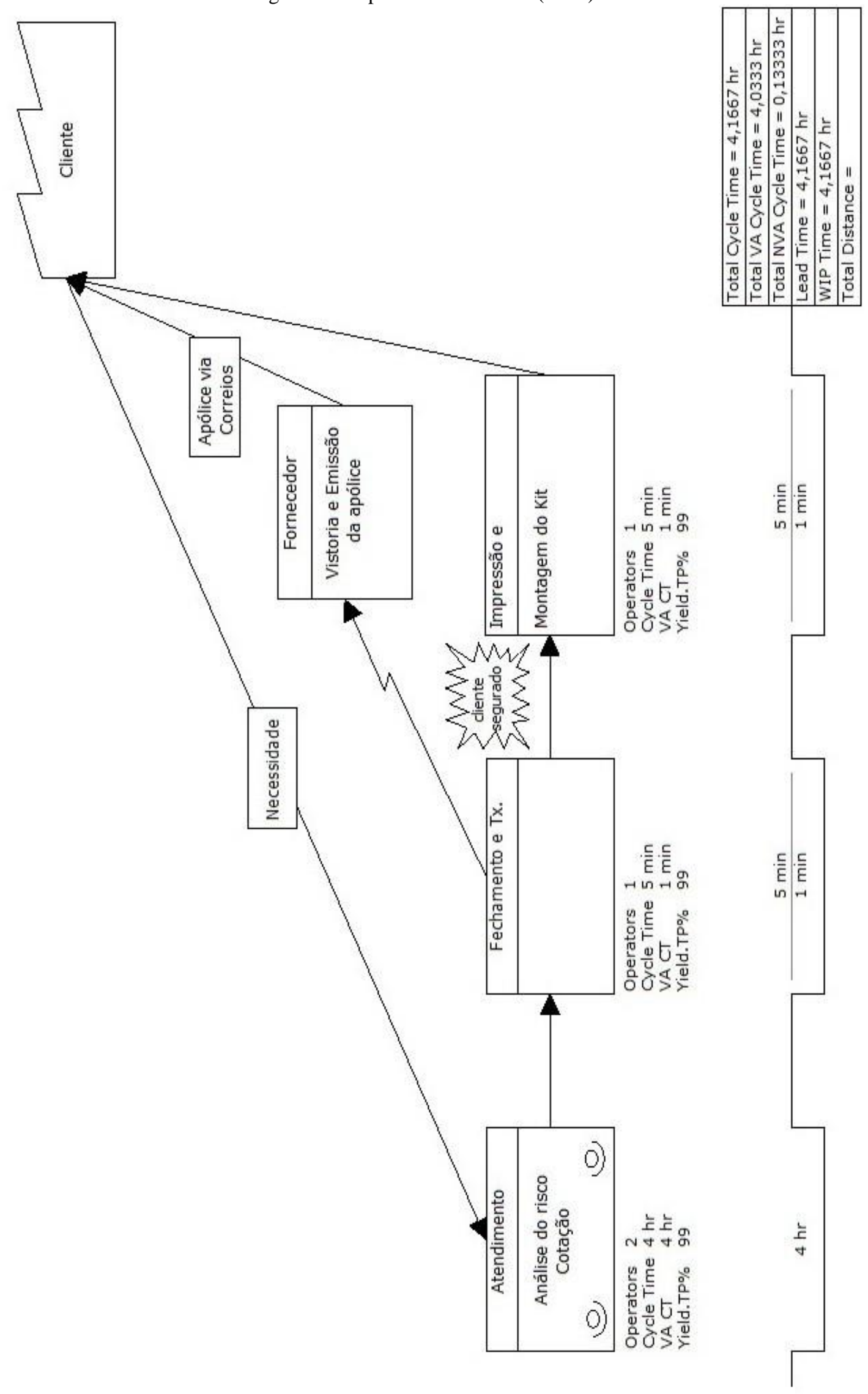

Fonte: Pesquisa de campo (2012) 
Nota-se que com a formação as melhorias sugeridas o MEF sofre uma forte alteração em seus índices, conforme a Tabela 2. Observa-se nesta tabela que os índices foram reduzidos significativamente.

Tabela 2 - Índices totais comparados MEA x MEF

\begin{tabular}{ccc}
\hline Índice & Valores MEA & Valores MEF \\
\hline Tempo de ciclo total & $168 \mathrm{~h}$ & $4,16 \mathrm{~h}$ \\
Tempo de VA & $20,33 \mathrm{~h}$ & $4,03 \mathrm{~h}$ \\
Tempo de NVA & $147,67 \mathrm{~h}$ & $0,13 \mathrm{~h}$ \\
Lead time & $192 \mathrm{~h}$ & $4,16 \mathrm{~h}$ \\
\hline
\end{tabular}

Fonte: Pesquisa de campo (2012)

Concluindo, percebe-se que a abordagem Lean pode trazer significativas contribuições para a análise de processos em empresas prestadoras de serviços. Notadamente, a análise foi baseada na dimensão tempo, acreditando que o cliente que deseja contratar um seguro queira fazê-lo o no menor tempo possível.

Interessante que no caso da corretora de seguros, a proposta do MEF, pode influenciar não só o processo em si, mas também outras decisões e políticas adotadas pela empresa tradicionalmente, como o caso da seleção da carteira de fornecedores e da priorização do atendimento ao cliente dentro da empresa e não mais via email.

Especialmente com relação a evitar o atendimento via emails, pode ser questionada, imaginando que um cliente não tenha tempo para ir à empresa e definir com ajuda de um especialista a melhor opção. Em todo o caso o métier de uma empresa de prestação de serviços de corretagem é justamente ajudar seus clientes a definir a melhor opção de seguro. Por isso, o MEF proposto leva ambos, cliente e empresa, a uma aproximação desde o atendimento inicial até o fechamento da proposta.

\section{Conclusões}

Neste trabalho se realizou um mapeamento de processos em uma organização prestadora de serviços, norteando-se pelos princípios do pensamento enxuto. Para tanto, foi utilizada a ferramenta lean conhecida como mapeamento do fluxo de valor (MFV). O MFV é uma ferramenta que pode guiar a implementação de práticas de produção em diferentes tipos de processos produtivos. O objetivo foi identificar desperdícios e propor soluções de melhoria visando a geração de valor para o cliente.

Buscando atender os objetivos deste trabalho realizou-se o mapeamento do fluxo de valor atual e se projetou um estado futuro. A discussão sobre o mapa de estado futuro realizou-se com a presença da gerência da organização foco deste estudo. Embora, a implantação do estado futuro não tenha se iniciado até a conclusão deste artigo, os resultados preliminares demonstram a viabilidade da incorporação dos princípios enxutos no contexto do sistema produtivo analisado. 
Algumas ações sugeridas podem servir de orientação para o planejamento das ações de melhoria do processo e se concentram principalmente na frente de atendimento ao cliente, a seleção de fornecedores e a parte operacional. Essas medidas podem influenciar não só o processo em si, mas também outras decisões e políticas adotadas pela empresa tradicionalmente, com relação aos clientes e fornecedores.

Acredita-se que a aplicação do MFV em uma organização prestadora de serviços representa uma contribuição ao conhecimento, uma vez que o setor de serviços é pouco explorado por essa técnica e por outras técnicas de manufatura. Conforme se apresentou na parte teórica deste trabalho, o setor de serviços pode alcançar ganhos de competitividade a partir do emprego de modelos de gestão comumente presentes em organizações manufatureiras.

Como sugestão para estudos futuros, salienta-se a necessidade de se avaliar a fase de implementação do MFV, seja em sistemas de produção de bens ou serviços, uma vez que a literatura sobre sistemas de avaliação de desempenho apresenta que em torno de $70 \%$ das iniciativas de avaliação falham no processo de implementação (WAAL; COUNET, 2009; MACCUNN, 1998; NEELY; BOURNE, 2000). Sobre este aspecto, fatores como o comprometimento da alta gerência, a resistência dos colaboradores com o processo de mudança e a estrutura da organização devem ser levados em consideração.

\begin{abstract}
This paper develops the application of Value Stream Mapping (VSM) in an insurance broker. The VSM is a major tool and one of the first steps to implement the lean thinking in organizations. The source of competitive advantage in the insurance sector may be in the processes responsible for translate the real customer requirements and their materialization in the sale of the final product, the insurance policy. Thus, the MFV presents itself as an important tool to help insurance organizations in reducing waste in the production process and consequently in the generation of customer value. The application methodology followed the procedures suggested by Rother and Shook (2003). It is perceived that the Lean approach can bring significant contributions to the analysis of processes in organizations of the insurance sector. Notably, in the time dimension, believing that the client that wants to hire a secure want to do it in the shortest possible time.
\end{abstract}

Key-words: lean service; insurance broker; service management.

\title{
Referências
}

ELIAS, S. J. B.; OLIVEIRA, M. M. DE; TUBINO, D. F. Mapeamento do fluxo de valor : um estudo de caso em uma indústria de gesso. Revista ADMpg, v. 4, n. 1, p. 1-10, 2011.

FITZSIMMONS, J.A.; FITZSIMMONS, M. Administração de serviços: operações, estratégia e tecnologia de informação. Porto Alegre: Bookman, 4. ed., 2005.

HOLWEG, M. The genealogy of lean production. Journal of Operations Management, v. 25, n. 2, p. 420-437, mar 2007. cross ref

KRAFCIK, J.F. The triumph of the lean production system. Sloan Management Review (Fall), p. 41-52, 1988. 
LASA, I. S.; LABURU, C. O.; VILA, R. D. C. An evaluation of the value stream mapping tool. Business Process Management Journal, v. 14, n. 1, p. 39-52, 2008. crossref

LEVITT, T. The industrialization of service, Harvard Business Review, v. 54, n. 5, p. 32-43. 1976.

MCCUNN, P. The balanced scorecard, the eleventh commandment. Management Accounting, December, p. 34-6, 1998.

NEELY, A.; BOURnE, M. Why measurement initiatives fail. Measuring Business Excellence, v. 4, n. 4, p. 3-7, 2000. crossref

ROTHER, Mike.; SHOOK, John. Aprendendo a enxergar: mapeando o fluxo de valor para agregar valor e eliminar o desperdício. São Paulo: Lean Institute Brasil, 2003

SAlGADO, E. G.; MELLO, C. H. P.; SILVA, C. E. S. DA; ALMEIDA, D. A. DE. Análise da aplicação do mapeamento do fluxo de valor na identificação de desperdícios do processo de desenvolvimento de produtos. Gestão e Produção, v. 16, n. 3, p. 344-356, 2009. cross ref

SANTOS, L. C.; GOHR, C. F.; SANTOS, E. K. DOS. Aplicação do mapeamento do fluxo de valor para a implementação da produção enxuta na fábrica de fios de cobre. Revista Gestão Industrial, v. 7, n. 4, p. 118-139, 2011.

SELAU, L.; PEDÓ, G. B.; SENFF, D. DOS S.; SAURIN, T. A. Produção enxuta no setor de serviços: caso do hospital de clínicas de Porto Alegre - HCPA. Revista Gestão Industrial, v. 5, n. 1, p. 122-140, 30 mar 2009. cross ref

SELLITTO, M. A.; BORCHARDT, M.; PEREIRA, G. M. Presença dos princípios da mentalidade enxuta e como introduzi-los nas práticas de gestão das empresas de transporte coletivo de Porto Alegre. Produção, v. 20, n. 1, p. 15-29, mar 2010. cross ref

SHINGO, S. O sistema Toyota de produção: do ponto de vista da engenharia de produção 2 ed. Porto Alegre: Bookman, 1996.

WAAL, A. A. D.; COUNET, H. Lessons learned from performance management systems implementations. International Journal of Productivity and Performance Management, v. 58, n. 4, p. 367-390, 2009. crossref

WOMACK, J. P.; JONES, D. T. A mentalidade enxuta nas empresas: elimine o desperdício e crie riqueza. 6. ed. Rio de Janeiro: Campus, 2004.

ZILBER, S. N.; BRANCALIÃO, H. F. Da identificação de oportunidades a ação empreendedora: estudo de caso no setor sucroalcooleiro brasileiro. In: 32 Encontro da ANPAD, 2008, Anais... Rio de Janeiro: ANPAD, 2008, 1 CDROM.

ZOSCHKE, A. C. K.; PEREIRA, C. Marketing de relacionamento para fidelização de clientes: um estudo na Oriento corretora de seguros, em Blumenau - SC. Revista Interdisciplinar Científica Aplicada, Blumenau, v.1, n.4, p.01-19, Sem II. 2007.

\section{Dados dos autores}

Nome completo: Darlan José Roman

Filiação institucional: Universidade Federal de Santa Catarina - UFSC

Departamento: Centro de Pós-Graduação em Administração - CPGA

Função ou cargo ocupado: Doutorando

Endereço completo para correspondência: CPGA / Centro Sócio-Econômico - Universidade Federal de Santa Catarina - Campus Universitário Trindade. Bairro Trindade - CEP 88040-900 -

Florianópolis - Santa Catarina - Brasil

Telefone para contato: (48) 37219393 
e-mail: darlanroman@yahoo.com.br

Nome completo: Jamur Johnas Marchi

Filiação institucional: Universidade Federal de Santa Catarina - UFSC/ Universidade Federal do Pampa - Unipampa

Departamento: Centro de Pós-Graduação em Administração - CPGA/ Departamento de Ciências da Administração

Função ou cargo ocupado: Doutorando/ Professor Assistente

Endereço completo para correspondência: CPGA / Centro Sócio-Econômico - Universidade Federal de Santa Catarina - Campus Universitário Trindade. Bairro Trindade - CEP 88040-900 -

Florianópolis - Santa Catarina - Brasil

Telefone para contato: (48) 37219393

e-mail: jamur.marchi@unipampa.edu.br

\section{Nome completo: Fernando Antônio Forcellini}

Filiação institucional: Universidade Federal de Santa Catarina - UFSC

Departamento: Programa de Pós-Graduação em Engenharia de Produção - PPGEP

Função ou cargo ocupado: Professor Associado

Endereço completo para correspondência: Universidade Federal de Santa Catarina, Departamento de Engenharia de Produção - Trindade - Cep: 88040-900 - Florianópolis, SC - Brasil - Caixapostal: 476

Telefone para contato: (48) 33317101

e-mail: forcellini@deps.ufsc.br

\section{Nome completo: Rolf Hermann Erdmann}

Filiação institucional: Universidade Federal de Santa Catarina - UFSC

Departamento: Centro de Pós-Graduação em Administração - CPGA

Função ou cargo ocupado: Professor Associado

Endereço completo para correspondência: CPGA / Centro Sócio-Econômico - Universidade Federal de Santa Catarina - Campus Universitário Trindade. Bairro Trindade - CEP 88040-900 -

Florianópolis - Santa Catarina - Brasil

Telefone para contato: (48) 37219393

e-mail: erdmann@cse.ufsc.br

Submetido em: 18/10/2012

Aceito em: 18/12/2013 